\title{
FORNECIMENTO DE MATERIAIS ESCOLARES ÀS ESCOLAS PÚBLICAS DO RIO GRANDE DO SUL (1882-1913)
}

SCHOOL MATERIAL SUPPLY TO PUBLIC SCHOOLS IN RIO GRANDE DO SUL (1882-1913)

SUMINISTRO DE MATERIALES ESCOLARES A LAS ESCUELAS PÚBLICAS DE RIO GRANDE DO SUL (1882-1913)

\author{
MICHEL, Caroline Braga' \\ PERES, Eliane ${ }^{2}$
}

\begin{abstract}
RESUMO
Este artigo insere-se no campo da cultura material escolar e analisa o fornecimento de materiais escolares às escolas públicas gaúchas pelo governo do estado entre os anos de 1882 e 1913. Os dados foram coletados em livros de registros de fornecimento de materiais, em contratos para fornecimento de material escolar firmados entre a Inspetoria da Instrução Pública e os fornecedores, em recibos e em editais de seleção de fornecimento de materiais divulgados no jornal A Federação. Foram, assim, identificados os principais fornecedores de materiais escolares, as condições dos contratos e a variedade de materiais comprados e fornecidos às escolas no período.
\end{abstract}

Palavras-chave: Cultura material escolar. Escola Pública. Materiais escolares. Rio Grande do Sul.

\section{ABSTRACT}

This study is developed in the field of school material culture and analyzes the supply of school materials to public schools in Rio Grande do Sul by the state government, between the years 1882 and 1913. Data were collected in material supply records, in the contracts for school material supply signed between the Inspectorate of Public Instruction and suppliers, in receipts, and in the material supply selection notices published in the newspaper A Federação. Results show the main suppliers of school materials, as well as the contract conditions and the variety of materials bought and delivered to schools in the period.

Keywords: Descen School material culture. Sublic School. School materials. Rio Grande do Sul.

\section{RESUMEN}

Este artículo se inserta en el campo de la cultura material escolar y analiza el suministro de materiales escolares a las escuelas públicas riograndenses bajo el gobierno del estado entre los años de 1882 y 1913. Los datos han sido recogidos de libros de registros del suministro de materiales, de contratos para el suministro de material escolar firmados entre la Inspetoria da Instrução Pública y los proveedores, recibos y de los anuncios de selección de suministro de materiales publicados en el periódico A Federação. De este modo han sido identificados los principales proveedores de materiales escolares, las condiciones de los contratos y la variedad de materiales comprados y suministrados a las escuelas en el período.

Palabras clave: Cultura material escolar. Escuela pública. Materiales escolares. Rio Grande do Sul.

\footnotetext{
1 Instituto Federal Farroupilha - IFFar - Rio Grande do Sul - Brasil

2 Universidade Federal de Pelotas - UFPel - Rio Grande do Sul - Brasil
} 


\section{INTRODUÇÃO}

$\mathrm{Na}$ última década do século $\mathrm{XIX}$, assim como nas primeiras do século $\mathrm{XX}$, em função dos discursos e dos projetos do Partido Republicano Rio-Grandense (PRR), sob forte influência positivista, o Rio Grande do Sul passou por significativas mudanças de ordem econômica, política, cultural e educacional, dentre elas, a expansão do sistema público de ensino (TAMBARA, 1995; GIOLO, 1997; CORSETTI, 1998, PERES, 2000).

Nesse processo de expansão e de consolidação de um sistema educacional, talvez umas das medidas mais expressivas tenha sido a criação dos colégios elementares em 1909. Conforme Peres (2000), a criação dessas instituições representou um dos momentos mais importantes na estruturação do sistema público de ensino primário do Estado no início do século XX. Essa mudança significou a institucionalização da escola graduada e com ela uma nova organização escolar foi estabelecida: o ensino seriado com um/a professor/a responsável por cada classe, várias salas de aula funcionando em um único prédio sob a responsabilidade de um diretor, a adoção do ensino intuitivo ${ }^{3}$, o uso mais racional do material didático, a modernização dos métodos e procedimentos de ensino, entre outros ${ }^{4}$. É preciso relembrar que se trata, de fato, de um modelo escolar que se impôs no Brasil no início do século XX, no contexto da ordem republicana e que previa uma organização mais complexa e racional da escola (SOUZA, 1998).

Assim, o contexto educacional do final do século XIX e das primeiras décadas do século XX, com a nova organização escolar e com o aumento significativo do número de escolas e de matrículas no referido período, ${ }^{5}$ contribuiu para a criação e o fortalecimento de um mercado editorial e didáticopedagógico, uma vez que esses fatores impulsionaram os discursos e as práticas voltadas para o uso de uma variedade de materiais pedagógicos, relacionados às modernas concepções de ensino da época, caracterizando uma verdadeira indústria escolar. Nesse sentido é preciso considerar que:

\footnotetext{
${ }^{3}$ Desde a segunda metade do século XIX, o método intuitivo aparece fortemente no discurso educacional brasileiro como o mais adequado para a instrução da população. Preconizava-se a conveniência da educação baseada no ensino pelos sentidos. Segundo Valdemarin (2004), o método pode ser sintetizado em dois termos: observar e trabalhar. Observar significa progredir do concreto para o abstrato, dos sentidos para a inteligência. Trabalhar consiste em fazer do ensino e da educação na infância uma oportunidade para a realização de atividades concretas, similares àquelas da vida adulta.

${ }^{4}$ É importante salientar, como afirmam Peres (2000) e Gil (2016), que a nova cultura escolar que se impôs com a criação desses colégios não representou uma ruptura imediata do modelo até então existente. Ainda que essa nova organização escolar tenha tido um papel importante no processo histórico de modernização do sistema de ensino público gaúcho, ela foi sendo instalada de forma gradativa, levando algumas décadas para se consolidar.

5 Nas primeiras décadas do século XX houve um aumento do número de escolas e de matrículas no Rio Grande do Sul. Comparativamente, em 1895, havia o registro de 625 escolas; já em 1910 o registro era de que havia mil escolas no estado gaúcho, ou seja, um aumento significativo. Do mesmo modo, o número de matrículas ampliou-se de 28.775, em 1895, para 64.000, em 1910 (GIOLO, 1997). Outro dado importante é em relação à alfabetização da população. Nesse período, virada do século, as taxas de analfabetismo decaíram no Rio Grande do Sul: de 76,8\%, em 1872 para 69,7\%, em 1890 (FERRARO \& KREIDLOW, 2004). Em 1920, essa taxa era de $53,8 \%$ da população com cinco anos e mais (FERRARO, 1985). Há, portanto, uma relação direta entre a ampliação da alfabetização e da escolarização no Estado e a chamada indústria e comércio escolares, aqui analisados.
} 
A 'arte de ensinar' tal como a concebia a moderna pedagogia que circulou no Brasil em fins do século XIX e início do século XX, conformando iniciativas de reforma escolar, é pedagogia prática. [...] Como artes de saber-fazer-com, ensino e aprendizagem, são práticas fortemente atreladas à materialidade dos objetos que lhes servem de suporte (CARVALHO, 2001, p. 142).

Em consonância com essa assertiva, os registros do período entre o final do século XIX e as primeiras décadas do século XX no Rio Grande do Sul evidenciam uma multiplicidade de materiais escolares que eram solicitados pelos/as professores/as, bem como fornecidos pelo Estado às aulas públicas. Se por um lado isso denota certo investimento financeiro por parte do Estado no ensino público - o "Estado-comprador" -, por outro, ajuda a explicar o crescimento de uma indústria e comércio escolares no contexto da educação gaúcha, entendida como tempo e espaço de investimento, produção, venda, compra e distribuição de materiais didáticos.

A investigação desses diferentes materiais escolares, entendidos como a cultura material da escola, permite compreender que "os materiais só adquirem uma existência, enquanto tais, porque estão diretamente ligados à produção de determinado conhecimento escolar" (FELGUEIRAS, 2005, p. 159). Logo, não existem "materiais soltos, sem gêneses e, consequentemente, sem valor social e político" (IBIDEM, p. 161).

Assim, considerando a ideia dos materiais escolares como mercadorias, do Estado-comprador e provedor desses objetos às aulas públicas e do crescimento de uma indústria e comércio escolares, necessária para os novos tempos de crescimento e ampliação do sistema público de ensino, o objetivo principal da pesquisa que resultou neste artigo foi identificar e analisar os materiais escolares adquiridos pelo estado do Rio Grande do Sul na virada do século XIX para o XX, momento chave na educação pública gaúcha. Com os documentos localizados, quais seja, livros de registros de fornecimento de materiais para as escolas públicas (1882-1911), contratos para fornecimento de material escolar entre a Inspetoria da Instrução Pública e os fornecedores (1898-1911), recibos (1913) e notícias e editais de seleção e de fornecimento dos materiais escolares que foram divulgados no jornal A Federação (1889-1913), foi possível colocar questões como, por exemplo, quais materiais eram fornecidos pelo Estado às aulas públicas? Quem eram os fornecedores selecionados para a distribuição dos objetos? Como eles eram selecionados? Quais as condições estabelecidas nos contratos de compra e de venda dos materiais didáticos? Assim, o objetivo principal deste artigo é, na medida do possível, responder as questões propostas que emergiram da documentação pesquisada e que cobrem o período de 1882 a 1913. Em razão disso, dividiu-se o artigo em duas seções: (i) materiais escolares fornecidos pelo estado e (ii) fornecedores e termos dos contratos. Esses dois aspectos só foram possíveis de serem abordados em razão da localização dos importantes e inexplorados documentos localizados na pesquisa e que estão salvaguardados no Arquivo Histórico do Rio Grande do Sul, em Porto Alegre. 


\section{MATERIAIS ESCOLARES FORNECIDOS PELO ESTADO}

É preciso considerar que com a expansão do sistema público de ensino abriu-se "um leque para a intromissão da indústria no universo escolar" (VIDAL \& GASPAR, 2010, p. 32), não apenas como fornecedora de materiais escolares, "mas também como produtora de novas necessidades impulsionando o comércio escolar" (IBIDEM, p. 32). Nessa direção é preciso considerar que há um "jogo de interesses que entrelaça o pedagógico, o Estado e a indústria" (IBIDEM, p. 33).

Para o caso específico do Rio Grande do Sul não foi diferente. Os dados da pesquisa revelam a relação entre o Estado, algumas casas comerciais e as demandas e necessidades de professores/as e alunos/as, em um verdadeiro 'jogo entrelaçado de interesses'.

Assim, considerando os registros dos livros de materiais fornecidos às aulas públicas no período de 1882 a 1911, de recibos de 1913 e de um livro de registro de contratos assinados entre o Estado e os fornecedores de materiais escolares entre os anos de 1898 e 1911, foi possível identificar o fornecimento de uma diversidade de objetos, os quais contemplavam não só materiais para o ensino de determinadas matérias escolares, mas também móveis e utensílios escolares, materiais de limpeza e higiene, materiais para a escrituração escolar utilizados na organização administrativa e pedagógica das instituições, etc. O Quadro 1, apresentado a seguir, ilustra alguns desses objetos que aparecem nos documentos consultados.

Quadro 1: Materiais presentes em listas de fornecimento às aulas públicas, recibos e em contratos de compra e venda firmados entre as casas comerciais e o Estado (1882-1913) ${ }^{6}$.

\begin{tabular}{|c|c|c|c|c|}
\hline $\begin{array}{l}\text { Livros e materiais } \\
\text { didático- } \\
\text { pedagógicos }\end{array}$ & $\begin{array}{l}\text { Utensílios e } \\
\text { instrumentos de } \\
\text { escrita }\end{array}$ & Móveis escolares & $\begin{array}{c}\text { Materiais de } \\
\text { limpeza, higiene e } \\
\text { uso pessoal }\end{array}$ & $\begin{array}{l}\text { Materiais de } \\
\text { escrituração escolar }\end{array}$ \\
\hline $\begin{array}{l}\text { livros } \\
\text { escolares } \\
\text { (Geografia, } \\
\text { História, } \\
\text { Matemática, } \\
\text { etc); } \\
\text { cartilhas; } \\
\text { mapas de } \\
\text { sistema } \\
\text { métrico; } \\
\text { mapa } \\
\text { Império; do } \\
\text { mapa das }\end{array}$ & $\begin{array}{l}\text { penas de aço e } \\
\text { de pedra; } \\
\text { penas para } \\
\text { ardósias; } \\
\text { ardósias; } \\
\text { réguas; } \\
\text { canivetes; } \\
\text { lápis de pedra e } \\
\text { para papel; } \\
\text { caneta de latão e } \\
\text { de madeira; } \\
\text { litros de tinta; } \\
\text { tinta em pó; }\end{array}$ & $\begin{array}{l}\text { armários de } \\
\text { louça; } \\
\text { escrivaninhas } \\
\text { com braço; } \\
\text { classes; } \\
\text { cadeiras } \\
\text { comuns; } \\
\text { mesas; } \\
\text { bancos; } \\
\text { estrados; } \\
\text { armários; } \\
\text { cabides; } \\
\text { escudos; }\end{array}$ & $\begin{array}{l}\text { urinóis; } \\
\text { campainhas; } \\
\text { copos de folha; } \\
\text { toalhas de linho; } \\
\text { copos de vidro; } \\
\text { garrafas finas } \\
\text { de barro para } \\
\text { água; } \\
\text { toalhas de linho } \\
\text { para mãos; } \\
\text { vassouras } \\
\text { americanas; } \\
\text { espanadores }\end{array}$ & $\begin{array}{l}\text { livros em branco; } \\
\text { livros para } \\
\text { matrícula; } \\
\text { livro para faltas } \\
\text { diárias; } \\
\text { livro para termos } \\
\text { de visitas e atas; } \\
\text { livros para } \\
\text { inventários; } \\
\text { livro para } \\
\text { correspondência } \\
\text { oficial; } \\
\text { envelopes e }\end{array}$ \\
\hline
\end{tabular}

\footnotetext{
${ }^{6}$ Optou-se pela atualização da grafia.
} 


\begin{tabular}{|c|c|c|c|}
\hline $\begin{array}{l}\text { províncias; } \\
\text { mapa mundi; } \\
\text { globo } \\
\text { terrestre; } \\
\text { tabuletas com } \\
\text { armas } \\
\text { imperiais; } \\
\text { percevejos; } \\
\text { barbante } \\
\text { pardo e de } \\
\text { cor; } \\
\text { campainhas; }\end{array}$ & $\begin{array}{l}\text { giz; } \\
\text { esponjas; } \\
\text { resmas de papel; } \\
\text { lápis de cor e de } \\
\text { borracha; } \\
\text { traslados; } \\
\text { caligráficos } \\
\text { cartonados; } \\
\text { folhas de mata- } \\
\text { borrão; }\end{array}$ & $\begin{array}{l}\text { grandes de } \\
\text { penas; }\end{array}$ & $\begin{array}{l}\text { papéis para } \\
\text { carta; }\end{array}$ \\
\hline
\end{tabular}

Fonte: Quadro elaborado pelas autoras a partir das listas de fornecimento às aulas públicas, de recibos e de contratos de compra e venda firmados entre casas comerciais e o Estado (1882-1913).

Um aspecto importante ao identificar a cultura material escolar é pensar em que medida a "materialidade expressa práticas educacionais, como evidencia aspectos da organização escolar, como indica finalidades socais e culturais da escola, como posiciona discursivamente alunos e professores" (PERES \& SOUZA, 2011, p. 54). Assim, não basta listar os materiais, é preciso observar que nesse período havia escolas urbanas, escolas isoladas, aulas públicas (muitas vezes com uma única sala de aula e um único professor para todos os adiantamentos), a coexistência do ensino individual e coletivo, a divulgação e a experimentação do método intuitivo, a expansão da produção didática nacional, entre outras inovações pedagógicas. Além disso, o período que compreende o final do século XIX e as primeiras décadas do século $X X$ marca também o momento de investimento do Estado na profissionalização docente. A Escola Normal de Porto Alegre, por exemplo, foi criada em 1869. Esses acontecimentos, entre outros, fomentaram a indústria e o comércio escolares.

Em relação ao item livros e materiais didático-pedagógicos, destacou-se, conforme apresentado no Quadro 1, principalmente os livros e os mapas. Nos dados coletados chama a atenção, entre outros exemplos, os registros de compra e distribuição de livros de Lição de Coisas, como, por exemplo, em 1898, em que 125 volumes da obra Licçoes de cousas, de Saffray, foi recebida pelo Almoxarifado da Instrucção Publica e dessas, 96 foram distribuídos às escolas (LIVRO I - 197, 18981903). Esse dado é revelador da presença do método intuitivo nas aulas públicas do estado no final do século XIX.

Outro destaque, dos muitos que a documentação permite fazer, é, por exemplo, o dado referente à compra pelo Estado, em 1903, de 15.000 Cartilhas Samorim e 25 "Cartilhas João de Deus"7 (LIVRO I - 197, 1898-1903). Além dos livros e mapas, alguns outros materiais aparecem nas listas a partir de uma determinada data como, por exemplo, o globo terrestre que, conforme a documentação, passou a ser distribuído a partir de 1899 às escolas públicas.

\footnotetext{
${ }^{7}$ Em outros trabalhos já analisamos esse fenômeno (MICHEL \& PERES, 2018; PERES \& MICHEL, 2018). 
Sobre os utensílios e instrumentos de escrita, para um período de trinta anos (1882-1913), há registros de diferentes suportes e instrumentos utilizados para as práticas de escrita, tanto de alunos/as, quanto de professores/as: penas de aço e de pedra, canivetes, ardósias, lápis de pedra e para papel, caneta de latão e de madeira, litros de tinta, giz, esponjas, resmas de papel, lápis de cor e de borracha.

A concomitância de diferentes instrumentos e suportes de escrita é perceptível como no caso da ardósia e do papel, por exemplo. A existência desses materiais de escrita revela que, nesse período, na escola primária, conviviam "suportes de escrita reutilizáveis (lousa) e não reutilizáveis (caderno e papel), o que dá ao registro escrito escolar produzido pelos alunos, um caráter ora visível, ora efêmero" (FRADE, 2008, p. 4).

Sobre a ardósia, destaca-se a compra de 10.000 delas, em 1903 (LIVRO I - 197, 1898-1903). A ardósia, que não era mais utilizada em alguns países como o Uruguai, por exemplo, por ser considerada contrária aos preceitos de higiene (MICHEL, 2017), ainda era distribuída e usada nas escolas públicas gaúchas nos primeiros anos do século $X X$, uma vez que aparece ainda nas listas de materiais comprados pelo Estado em 1911.

Em relação aos móveis escolares, enfatizou-se armários, escrivaninhas, classes, cadeiras, mesas, bancos, estrados, cabides. Em relação às classes ou carteiras escolares, pode-se destacar que os diferentes modelos e seus distintos usos no espaço escolar devem ser compreendidos, como ressalta Vidal (2009), associados aos ideais e às propostas pedagógicas que circulavam em determinado período. O uso dos modelos das carteiras individuais, por exemplo, é decorrente de uma crítica dos médicos higienistas que passa a vigorar a partir do final do século XIX. Eles "percebiam, nas diferentes alturas entre banca e banco e na falta de respaldar, as causas da miopia e da escoliose entre os escolares" (VIDAL, 2009, p. 33). Assim, a solução era posta com o uso de um mobiliário específico que "além de regularem a altura ideal entre o assento e a mesa, normatizavam a distância entre o encosto do banco e o borde da mesa e a inclinação desta última" (IBIDEM, p. 34).

No que tange ao item materiais de limpeza, higiene e uso pessoal, identificou-se o fornecimento de urinóis, copos, toalhas, garrafas, vassouras, etc. Alguns dados mais específicos despertam especial atenção: por exemplo, o recebimento de 132 urinóis de louça pelo Almoxarifado da Instrucção Publica para serem distribuídos às escolas públicas do Rio Grande do Sul, em 1898 (LIVRO I - 197, 18981903). Esse aspecto precisa ser pensado no contexto das condições concretas dos espaços urbanos e rurais do século XIX. Aspectos como inexistência de banheiros, de saneamento, de água potável, de luz, etc., precisam ser considerados. Nesse sentido, escola e urbanização, escola e condições sócioeconômicas e cultura material escolar só podem ser compreendidas articuladamente.

Outros dados ainda deixam dúvidas quanto à sua utilidade e sentido no contexto escolar como, por exemplo, toalhas de linho e toalhas de linho para mãos. Nesse sentido,

Contamos com a limitação de aproximarmos do conteúdo material apenas através de documentos escritos. Por isso, ainda temos o problema de, no caso dos objetos, da dificuldade em identificar o que são, para que servem, e como eram utilizados, principalmente por alguns deles não pertencerem ao nosso universo cultural atual. (VEIGA, 2000, p. 6). 
Por fim, os materiais de escrituração escolar, livros em branco, livros para matrícula, para faltas diárias, para termos de visitas e atas, para inventários, para correspondência oficial, envelopes e papéis para carta, precisam ser compreendidos no contexto de uma escola que se pretendia mais racional e eficiente, por isso tornava-se mais burocrática.

Segundo Gil \& Hawat (2015), diversos suportes de escrita vão paulatinamente adentrando a escola moderna e se diversificando com o passar dos séculos. No Brasil, ainda segundo as autoras supracitadas, a escola instaurada no país "durante o século 19 e que foi alçada a signo de progresso no projeto republicano, assumiu a prática escriturística como elemento fundamental" (IBIDEM, p. 21). Nesse sentido, a escrituração escolar pretendia "organizar, fiscalizar, classificar e atestar as práticas de professores e alunos na escola". (IBIDEM, p. 21). A quantidade e ocorrências das solicitações e do fornecimento de livros para a escrituração escolar identificada na documentação pesquisada atestam essas premissas.

\section{FORNECEDORES E TERMOS DOS CONTRATOS}

Nos contratos firmados e registrados no Livro I - 196, há a indicação de que os mesmos foram lavrados respeitando o artigo 94 do Regulamento de 2 de Fevereiro de 1897, o qual dispõe o que segue:

\footnotetext{
Art. 94 - Em novembro de cada ano, o Inspetor Geral fará chamar concorrentes ao fornecimento não só dos moveis a que se refere a $2^{\mathrm{a}}$ parte do artigo anterior, como de livros, papel e objetos necessários ao serviço do ensino público e da Secretaria da Inspetoria Geral.

$1^{\circ} \mathrm{A}$ concorrência será aberta separadamente sendo móveis e utensílios mencionados em uma proposta; livros, papel e mais objetos de expediente em outra. Poderá ser aceita uma proposta, assim como poderão ser escolhidos em diversas os objetos, conforme o preço e qualidade. [...] (DECRETO n 89, de 2 de fev. de 1897, p. 190).
}

Alguns editais de tais concorrências foram localizados no jornal $A$ Federação, o que indica que, provavelmente, a prática de divulgar os mesmos na imprensa era recorrente, ainda mais se tratando deste jornal que era o órgão oficial do Partido Republicano, o qual esteve na gestão do Estado no período em questão. No entanto, ao analisar os editais identificados, notou-se que em alguns anos eles foram publicados somente com a informação de que estava aberta a concorrência e em outros foram divulgados os materiais que estavam sendo licitados, conforme imagens expostas abaixo: 
Figura 1: Editais de concorrências para compra de materiais escolares

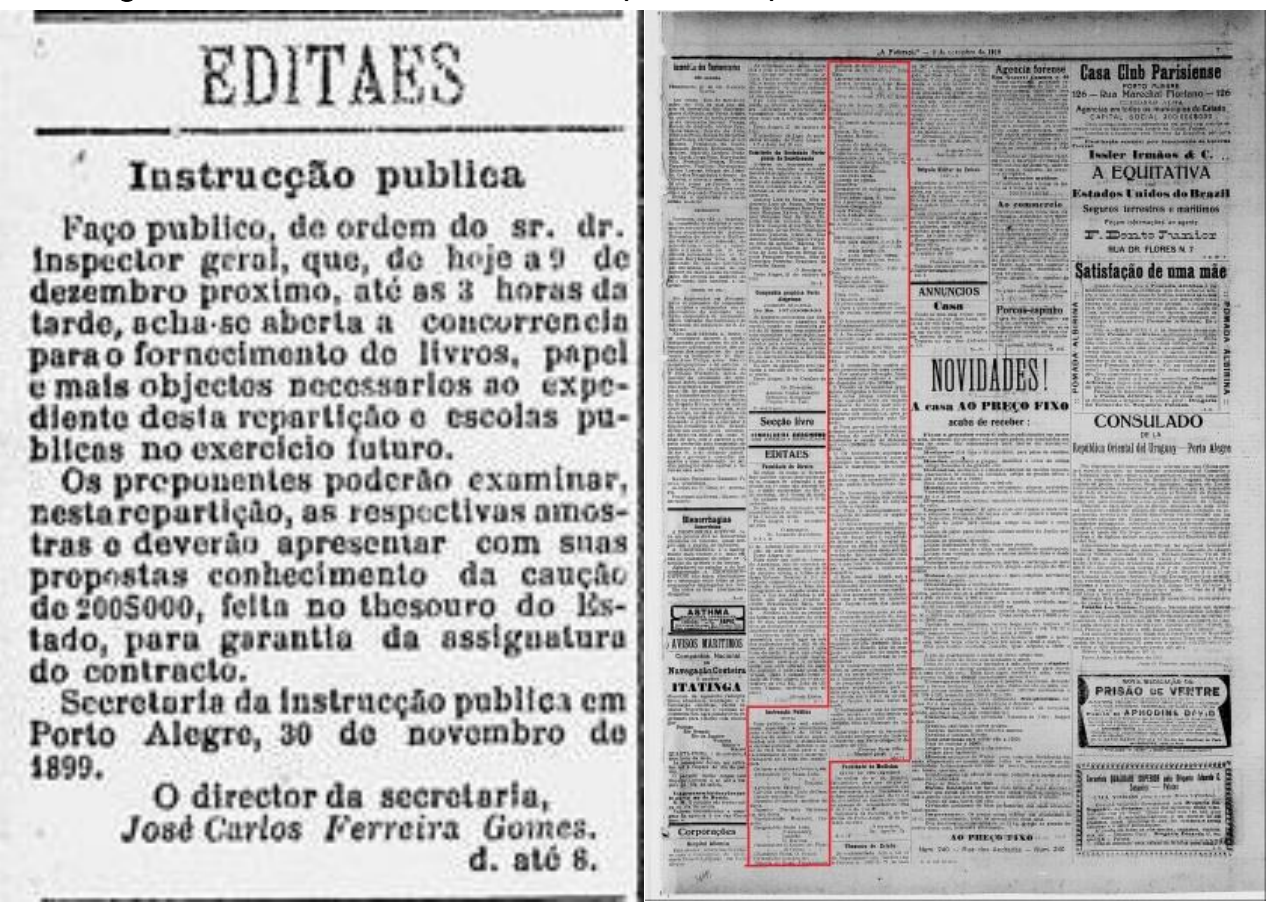

Fonte: A Federação (1889, ed. 273, p. 3) e A Federação (1913, ed. 255, p. 7).

Como é possível observar a partir da Figura 1, os anúncios que tinham discriminados os materiais escolares a serem licitados, eram bem maiores do que aqueles que simplesmente anunciavam a abertura do edital, uma vez que eles apresentavam maiores detalhes, como é o caso, por exemplo, dos livros, para os quais aparece o título da obra e o nome dos autores (Arithmetica, $1^{\text {a }}$, Souza Lobo; Arithmetica, $2^{\mathrm{a}}$, Souza Lobo; Arithmetica, Trajano, Cartilha primaria, João de Deus, etc.); para os utensílios escolares e demais objetos necessários ao expediente da Instrução Pública, eram mencionadas as especificações do produto como marca, número de folhas dos cadernos e quantidade, dúzia ou caixa, etc (Canetas de latão, dúzia; Canetas de madeira, dúzia; Cadernos de caligrafia, 20 fls.; Lápis Faber, dúzia; Lápis Ardósia, caixa; Livros para escrituração, 50 fls.; Papel pautado, 5 kilos, resma). Além disso, eram citadas nesses casos também as regras da concorrência, ou seja, as cláusulas que constariam, posteriormente, nos contratos firmados, quais sejam:

\footnotetext{
Os proponentes obrigar-se-á:

1) Para o fornecimento do material de ensino, as seguintes condições:

a) O fornecimento será feito especificamente e remetido a quem o Governo designar;

b) A fiscalização será exercida de acordo com as determinações do governo;

c) O pagamento será feito pelo Tesouro do Estado, em vista de conta processada nesta Repartição;

d) O contrato fica sujeito ao selo proporcional em suas contas;

e) Por qualquer infração, ficam os fornecedores sujeitos à multa de duzentos mil réis (200\$000); [...]. (Edital. A Federação, 1913, ed. 255, p. 7).
}

No processo de licitação para fornecimento de materiais escolares é importante destacar que, ao serem entregues as propostas, os fornecedores deveriam comprovar também a realização de um depósito caução no valor de $200 \$ 000$ réis para a garantia do contrato ( $A$ Federação, 1900, ed. 287). 
Posteriormente, então, era realizada uma análise por parte do Estado, presidida pelo diretor da Secretaria (DECRETO n 89, de 1897, Art. 10). Na seleção poderia ser aceita uma ou mais propostas, conforme o preço e a qualidade dos objetos. Ao término das avaliações, as mesmas eram enviadas ao Inspetor Geral e ao Secretário de Estado dos Negócios do Interior e Exterior. A respeito dos valores apresentados por cada fornecedor, salienta-se que não há muitas informações, foram raros os registros localizados nesse sentido. A Figura 2, a seguir, é ilustrativa de como esses dados apareciam, por vezes, na imprensa:

Figura 2: Resumo das propostas apresentadas na concorrência de materiais escolares do ano de 1909.

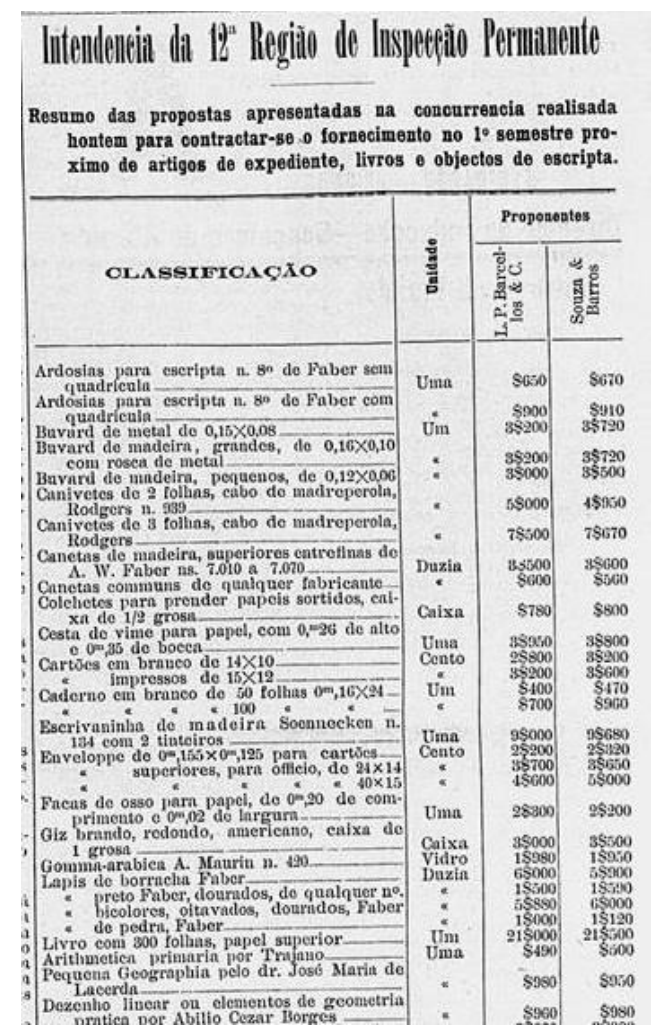

Fonte: A Federação (1909, ed. 231, p. 2).

Essa publicação no jornal chama a atenção pelo fato de que ao se comparar os valores e os utensílios descritos nela e nos contratos registrados no Livro I-196, por exemplo, não foram encontrados vários dos materiais. Destaca-se a descrição das ardósias de $n^{0} 8$ da Faber que, pelos preços individuais apresentados no quadro impresso no jornal, deveriam ser licitados pela L.P. Barcellos, uma vez que o objeto custava $\$ 900$ na referida casa editorial, enquanto na Souza e Barros ele era $\$ 10$ mais caro. Todavia, esse objeto escolar destinado à escrita não consta listado no contrato firmado com a referida empresa no ano de 1909. Do mesmo modo, há no registro do contrato a indicação de compra do Terceiro e do Quarto Livro de leitura de Hilário Ribeiro, que custariam respectivamente $\$ 259$ e $\$ 278$ réis cada um, mas eles não constam no resumo da publicação, Figura 2, exposta acima. 
A partir da análise do Livro I - 196, que tinha como objetivo firmar "os termos de contractos lavrados nesta Repartição" (LIVRO I - 196, 1898-1911), observou-se que no período de 1898 a 1911 forneceram materiais "ao expediente das escolas do Estado e da Secretaria da Inspectoria Geral da Instrucção Publica" (IBIDEM) os seguintes fornecedores:

Quadro 2: Fornecedores de materiais escolares (1898-1911)

\begin{tabular}{|c|c|c|}
\hline Fornecedor & Ano & $\begin{array}{c}\text { Quantidade de contratos } \\
\text { assinados }\end{array}$ \\
\hline Rodolpho José Machado & $1898-1904$ & 07 \\
\hline Carlos Augusto Reis & 1905 & 01 \\
\hline João de Araújo Bastos & 1907 & 01 \\
\hline Selbach e Mayer & 1909 & 01 \\
\hline L. P. Barcellos & $1909 ; 1911$ & 02 \\
\hline Souza e Barros & $1909 ; 1911$ & 02 \\
\hline Commercial Cunha Rentich & 1911 & 01 \\
\hline Afonso Selbach & 1911 & 03 \\
\hline
\end{tabular}

Fonte: Quadro produzido pelas autoras a partir dos dados do Livro I - 196 (1898-1911).

Como mostra o Quadro 2, os fornecedores de materiais escolares variaram no decorrer dos treze anos referentes à documentação localizada. Rodolpho José Machado, no entanto, aparentemente, foi o único que forneceu ao Estado os materiais por um período mais longo, de 1898 a 1904, constando, portanto, nesse período, os termos de seus contratos no documento investigado. Posteriormente a esse interstício, não há no livro assinatura de contratos com o referido fornecedor, tem-se apenas outras casas comerciais como responsáveis pelo fornecimento dos materiais escolares, sendo a Selbach e Mayer, a L. P. Barcellos e a Souza e Barros as mais recorrentes e que forneciam a maior quantidade de materiais. Tal dado merece mais atenção e o desenvolvimento de pesquisas específicas, mas indaga-se: seriam elas as mais "fortes" e as maiores casas comerciais no período que poderiam fornecer materiais escolares? Ofereciam mercadorias com um custo menor ao Estado? Tinham uma variedade maior de materiais a oferecer? Por ora, essas questões são apenas motes para a sequência da investigação.

Quanto aos outros três fornecedores que aparecem no Quadro 2, Carlos Augusto Reis, João de Araújo Bastos e Commercial Cunha Rentich, destaca-se que os seus respectivos contratos foram assinados para o fornecimento de materiais específicos. No caso do primeiro, trata-se da compra, por parte do Estado, de 4 mil coleções de cadernos de desenhos, do qual o referido contratado era o próprio autor. O segundo acordo, de 1907, foi firmado em virtude de João de Araújo Bastos possuir uma casa de marcenaria em Cachoeira, cidade a qual apresentava necessidade de adquirir móveis e artigos para as escolas públicas e, como frisado anteriormente, as compras de utensílios escolares e de móveis eram realizadas por editais e contratos diferentes. Por fim, o Commercial Cunha Rentich foi 
contratado para prover somente o livro didático intitulado "O Rio Grande do Sul", de J. Conte Guimarães, no ano de 1911.

Também é perceptível, a partir do Quadro 2, tanto algumas lacunas nos registros referentes aos anos de 1906, 1908 e 1910, uma vez que não há a assinatura de contratos registrados no livro, como também a concomitância de diferentes fornecedores em um mesmo ano, como em 1909 e 1911, em que os objetos foram comprados de mais um fornecedor, indicando, portanto, para a concorrência no mercado dos produtos escolares.

Ainda que não se tenham respostas para os aspectos mencionados anteriormente, algumas hipóteses ganham força na medida em que se entrecruza dados de pesquisa. Sobre as ausências de registros, por exemplo, cabe salientar que se localizou, para além dos contratos registrados no Livro I 196, outros dados que indicam os fornecedores de materiais escolares ao Estado gaúcho. No jornal $A$ Federação, por exemplo, no ano de 1903, há o registro do pagamento à Echenique Irmãos \& C. "a quantia de 450\$000, proveniente do fornecimento de 50 mapas geográficos do Estado à inspetoria geral da Instrução Pública" e a Dionysio G. de Magalhães "a quantia de 80\$, proveniente do fornecimento de um relógio para o colégio distrital desta capital" (A FEDERAÇÃO, 1903, ed. 169, p. 2). Outro dado nesse sentido são os recibos de entrega de material realizada pela Selbach \& Cia e pela R. da Fonseca \& Cia à aula mista sob a direção da professora D. Maria Innocencia Couto e Silva no ano de 1913, reproduzidos a seguir:

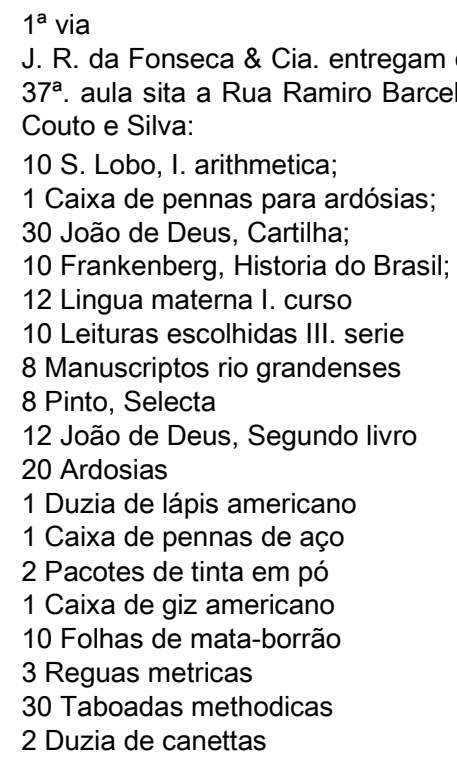

Fonte: Recibo de fornecimento de material à $37^{\mathrm{a}}$ aula, situada na Rua Ramiro Barcellos $\mathrm{n}^{\circ} 187$, sob a direção da professora D. Maria Innocencia Couto e Silva.

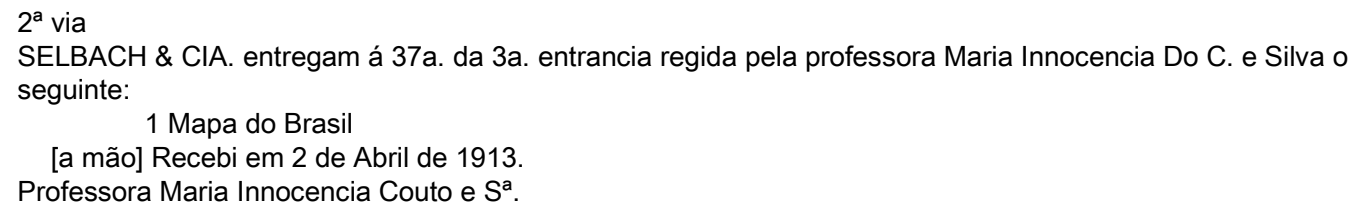

Fonte: Recibo de fornecimento de material à $37^{a}$ aula, situada na Rua Ramiro Barcellos $\mathrm{n}^{\circ} 187$, sob a direção da professora D. Maria Innocencia Couto e Silva. 
Esses dados implicam na ressalva de que, provavelmente, os fornecedores de materiais escolares não tenham sido somente aqueles que lavraram contrato no Livro analisado (Livro I - 196). Nesse sentido, amplia-se a lista de fornecedores ao Estado. Do mesmo modo, é possível que os acordos firmados tenham extrapolados o período descrito no livro, qual seja, entre 1898 e 1911 e que tenham sido registrados em outros livros e/ou documentos.

No que diz respeito à periodicidade, do total de 18 contratos registrados no Livro l-196 destacase que 03 foram assinados no mês de Janeiro (1899; 1901; 1904), 03 no mês de Fevereiro (1898; 1902; 1903), 01 em Março (1903), 07 no mês de Maio (1907; 1911), 03 em Agosto (1909) e 01 em Dezembro (1899), o que evidencia que a maior parte foi firmada nos primeiros meses do ano, indicando, assim, provavelmente, a periodicidade anual de contratação para fornecimento de objetos escolares, conforme previsto no artigo 94 do Decreto de 1897. A exceção está no ano de 1899, em que foram assinados dois contratos com Rodolpho José Machado, sendo um no mês de Janeiro e outro em Dezembro. Cabe frisar, desse modo, que nos anos de 1909 e 1911, embora exista mais de um contrato assinado, trata-se de fornecedores diferentes para o caso de 1909, ou de rubricas distintas como em 1911. Nesse ano foram assinados três contratos com Afonso Selbach, no entanto, um referia-se ao fornecimento de materiais para as escolas, outro para a Secretaria e outro para o encaixotamento e remessa dos materiais. Embora esse tenha sido o único contrato localizado com tal finalidade, isto é, a responsabilidade por encaixotamento e pela remessa de materiais de ensino e não pelo fornecimento de objetos às aulas públicas, essa prática já era realizada anteriormente. Ou seja, conforme consta na reportagem publicada no periódico investigado, no ano de 1900 "providenciou-se no sentido de ser paga ao cidadão Pedro Jacob Weber, agente do vapor Taquara a quantia de $312 \$ 000$, proveniente do transporte desta capital à vila da Taquara do Mundo Novo, de 21 volumes contendo fornecimento para escolas públicas dessa localidade" (A FEDERAÇÃO, 1900, ed. 242, p. 1).

Sobre as cláusulas e redação dos contratos, salienta-se que se observou que elas tiveram alterações no decorrer dos anos. Entre 1898 a 1904, por exemplo, possivelmente por se tratar do mesmo fornecedor, os itens a ser fornecidos foram redigidos no contrato em duas partes: (i) objetos necessários ao expediente das escolas do Estado e (ii) objetos fornecidos à Secretaria da Inspetoria Geral da Instrução Pública. Assim, na primeira parte constavam os materiais de ensino e os respectivos preços que haviam sido apresentados conforme amostras para "arrematação" tais como cartilhas, tinta fresca, tinteiros de vidro para as classes e para os professores/as, Pennas Mallat $n^{\circ}$. 10 e 12, lápis para ardósia, ardósias, canetas de madeira e de latão, papel filme pautado e liso, papel mata-borrão, giz quadrado, réguas métricas, campainhas de metal, entre outros objetos de ensino já salientados na primeira seção deste texto. E na segunda parte, os materiais para a Secretaria como, por exemplo, lápis Faber n. 2, de cor e de borracha, cadernos linho, papel linho pautado azul, copos de vidro, garrafas finas de barro para água, toalhas de linho para mãos, envelopes e papeis para cartas, vassouras americanas, espanadores, etc.

Os termos do acordo celebrado entre o Estado e os fornecedores até o ano de 1908 previam a obrigação de entrega das quantidades solicitadas e o respeito aos preços especificados nas propostas, como se observa na redação de uma das cláusulas que indicava que os objetos deveriam ser 
"entregues pelo fornecedor na arrecadação desta Inspetoria dentro do prazo de 48 horas a contar do pedido, sem ônus algum para o Estado" (LIVRO I- 196. Contrato, 1898, III Cláusula,). Caso houvesse descumprimento das condições apresentadas no contrato, os fornecedores seriam multados no valor de 200.000 mil réis. Estava previsto, ainda, que os contratados seriam pagos "pelo Tesouro do Estado à vista do recibo do Almoxarife lançado ou a nota do pedido e rubricado pelo Diretor da Secretaria" (LIVRO I -196. Contrato, 1898, VI Cláusula).

Nos contratos assinados a partir de 1909 são observadas modificações significativas não só nas cláusulas dos mesmos, mas também nas suas finalidades, uma vez que se tratando do mesmo fornecedor, tanto para os materiais de ensino como para os da Secretaria, os itens foram redigidos em contratos individuais, ou seja, há em 1911, por exemplo, um contrato assinado com Afonso Selbach para o fornecimento dos artigos necessários ao expediente da Inspetoria Geral da Instrução Publica e outro para o fornecimento nos estabelecimentos de ensino público. Além disso, os objetos destinados às aulas públicas não deveriam ser mais entregues na Secretaria de Instrução Pública, mas sim nas Intendências Municipais das próprias escolas. Para tanto, como prevê a redação do contrato: "O fornecimento será feito por escola e entregue pelo contratante 24 horas após a expedição do pedido, antes de ser encaixotado e remetido à Intendência do município respectivo que o entregará ao professor" (LIVRO I - 196. Contrato, 1911, II Cláusula). Desse modo, "os livros e material de ensino serão encaixotados após a fiscalização exercida pelo empregado a quem o Inspetor Geral designar" (LIVRO I - 196. Contrato, 1909, III Cláusula) e, posteriormente, então, enviados aos municípios.

Corrobora essas cláusulas a situação ocorrida com o contrato celebrado em 1907 com o cidadão João de Araújo Bastos para o fornecimento de móveis e artigos necessários exclusivamente às escolas públicas do município da Cachoeira. No mesmo, que previa a aquisição de classes, mesa com pés simples, mesa com pés torneados, pedras, armários, estrados, cadeira de braço, entre outros, a entrega dos móveis escolares deveria ser realizada na Intendência do Município, ficando a cargo desta a responsabilidade pela distribuição do mobiliário.

Considerando, portanto, que o envio dos materiais escolares era feito diretamente para os munícipios, o pagamento aos fornecedores ficava circunscrito aos recibos de entrega das Intendências Municipais. A partir disso, o tesouro do Estado realizava, então, o pagamento mediante conta documentada e rubrica do Inspetor Geral. Provavelmente em virtude dessa alteração no formato de entrega dos materiais adquiridos a partir de 1909 é que se tem o primeiro registro de celebração de um contrato para encaixotamento e remessa do material de ensino no ano de 1911, como já frisado anteriormente.

\section{CONSIDERAÇÕES FINAIS}

A documentação localizada acerca da compra e da distribuição de materiais escolares às escolas públicas gaúchas situa-se no período entre os anos de 1882 e 1913 e permite conhecer aspectos da cultura material escolar nesse contexto. Os dados da pesquisa revelam que um amplo comércio e uma indústria escolares foram estabelecidos no Rio Grande do Sul no momento de implantação do sistema público de ensino. Dos anos que antecederam a instalação da República à 
primeira década do século $\mathrm{XX}$, o estado gaúcho estabeleceu um vínculo comercial importante com várias casas comerciais e/ou prestadores de serviços para o provimento das escolas públicas no que diz respeito a materiais didático-pedagógicos, de higiene e limpeza, mobiliários, etc. Entre elas destacam-se: Rodolpho José Machado, Carlos Augusto Reis, João de Araújo Bastos, Selbach e Mayer, L. P. Barcellos, Souza e Barros, Commercial Cunha Rentich, Afonso Selbach, Echenique Irmãos \& C, Commercial Cunha Rentich, João de Araújo Bastos, J. R. da Fonseca \& Cia.

É preciso reafirmar, pois, que a escola como mercado e o Estado-comprador explicam-se pelo próprio avanço da escolarização com a expansão das escolas públicas, do investimento na profissionalização docente, do contexto das inovações pedagógicas, dos discursos republicanos, para o caso do Brasil em geral, e positivista para o caso específico do Rio Grande do Sul. Assim, nesse contexto, uma gama de materiais foi comprada e fornecida pelo Estado às escolas e aulas públicas. Nesse sentido, pode-se afirmar que o provimento das escolas - mesmo havendo dados que mostrem as precárias condições das escolas públicas no período - se inserem no esforço de modernizar e qualificar a escola. Os comerciantes, ao participar da licitação dos editais abertos pela Secretária da Instrução Pública, beneficiaram-se do momento em que, com a expansão do sistema público de ensino, houve um incremento nas vendas de produtos escolares, em um jogo que entrelaçava, como afirmaram Vidal \& Gaspar (2010), o pedagógico, o Estado e a indústria.

\section{REFERÊNCIAS}

1. A FEDERAÇÃO. Orgam do Partido Republicano. Porto Alegre, ed. 273, p. 3, 1889.

2. A FEDERAÇÃO. Orgam do Partido Republicano. Porto Alegre, ed. 287, p. 4, 1900.

3. A FEDERAÇÃO. Orgam do Partido Republicano. Porto Alegre, ed. 169, p. 2, 1903.

4. $\quad$ A FEDERAÇÃO. Orgam do Partido Republicano. Porto Alegre, ed. 231, p. 2, 1909.

5. A FEDERAÇÃO. Orgam do Partido Republicano. Porto Alegre, ed. 255, p. 7, 1913.

6. CARVALHO, Maria M. C. D. A caixa de utensílios, o tratado e a biblioteca: pedagogia e práticas de leitura de professores. In: VIDAL, Diana Gonçalves; HISDORF, Maria Lucia. (Orgs.) Brasil 500 anos: tópicos de história da educação. São Paulo: Edusp, 2001, p. 137-167.

7. CORSETTI, Berenice. Controle e Ufanismo: A escola pública no Rio Grande do Sul (1889-1930). Tese (Doutorado em Educação) Faculdade de Educação. Programa de Pós-Graduação em Educação. Universidade Federal de Santa Maria. Santa Maria. 537 f., 1998. 
8. FELGUEIRAS, Margarida L. Materialidade da cultura escolar. A importância da museologia na conservação/comunicação da herança educativa. Pro-prosições, v. 16, jan./abr. 2005. p. 87- 102.

9. FERRARO, Alceu R. Analfabetismo no Brasil: tendência secular e avanços recentes. Resultados preliminares. Cadernos de Pesquisa (Fundação Carlos Chagas. Impresso), São Paulo, v. 52, n.52, p. 25-33, 1985.

FERRARO, Alceu R.; KREIDLOW, Daniel. Analfabetismo no Brasil: configuração e gênese das desigualdades regionais. Educação e Realidade, Porto Alegre, v. 29, n.2, p. 179-200, 2004.

11. FRADE, Isabel Cristina A. da S. Cultura escrita no final do século XIX e início do século. XX em Minas Gerais: suportes, instrumentos e textos de. alunos e professores. ANPED, Caxambu, MG, 2008. Disponível em: www.anped.org.br/reunioes/31ra/1trabalho/GT10-4237--Int.pdf Acesso em 20, Dez, 2018.

GIL, Natália. "Pequenos focos de luz": as escolas isoladas no período de implantação do modelo escolar seriado no Rio Grande do Sul. Revista Brasileira de História da Educação, Maringá/PR, v. 16, n. 2 (41), abril/junho 2016. p. 261-284.

GIL, Natália; HAWAT, Joseane. O tempo, a idade e a permanência na escola: um estudo a partir dos livros de matrícula (Rio Grande do Sul, 1895-1919). Revista História da Educação [Online] Porto Alegre v. 19 n. 46 Maio/ago., 2015 p. 19-40. História e Filosofia da Educação). Faculdade de Educação. Universidade de São Paulo. São Paulo. 427f. 1997.

MICHEL, Caroline Braga; PERES, Eliane. Cartilha Mestra e Cartilha Samorim - Recreativa e Instructiva: uma análise comparativa. In: $24^{\circ}$ Encontro da ASPHE, 2018, São Leopoldo. Anais do 24 Encontro da ASPHE. São Leopoldo: Unisinos, 2018. v. 1. p. 1123-1137.

MICHEL, Caroline Braga. Missão de estudos ao Uruguai: mudanças no sistema de ensino do Rio Grande do Sul (1913-1927) (Tese de Doutorado). Programa de Pós-Graduação em Educação, Universidade Federal de Pelotas, Pelotas, RS. 283 f. 2017.

PERES, Eliane. Aprendendo formas de pensar, sentir e de agir. A escola como oficina da vida: discursos pedagógicos e práticas escolares da Escola Pública Primária Gaúcha (1909-1959). Programa de Pós-Graduação em Educação. Universidade Federal de Minas Gerais. Belo Horizonte, 507f. 2000. 
PERES, Eliane; SOUZA, Gizele de. Aspectos teórico-metodológicos da pesquisa sobre cultura material escolar (im)possibilidades de investigação. In: CASTRO, César Augusto. (Org.). Cultura Material Escolar: a escola e seus artefatos (MA, SP, PR, SC e RS, 1870-1925). 1ed. São Luís: EDUFMA: Café \& Lápis, 2011, v. 1, p. 43-68.

PERES, Eliane; MICHEL, Caroline Braga. Circulação e fornecimento de livros escolares no Rio Grande do Sul no final do século XIX e início do século XX (1873-1921) In: PERES, Eliane; RAMIL, Chris de Azevedo (Orgs.) Produção e circulação de livros didáticos no Rio Grande do Sul nos séculos XIX e XX. Curitiba: Editora Appris, 2018.

RIO GRANDE DO SUL. Decreto $n^{\circ}$ 89, de 2 de fevereiro de 1897. Reorganiza a instrução primária no Estado. Disponível em https://repositorio.ufsc.br/handle/123456789/100091. Acesso em 29 Abr 2019.

21. RIO GRANDE DO SUL. SECRETARIA DA INSTRUCÇÃO PUBLICA. Livro I-182. Livro de registro do fornecimento de material para as escolas (1882-1887). Arquivo Histórico do Rio Grande do Sul, Porto Alegre. RIO GRANDE DO SUL. SECRETARIA DA INSTRUCÇÃO PUBLICA. Livro I - 196. Livro nº 1 de registro de contrato com fornecedores de móveis escolares (1898-1911). Arquivo Histórico do Rio Grande do Sul, Porto Alegre.

RIO GRANDE DO SUL. SECRETARIA DA INSTRUCÇÃO PUBLICA. Livro I, 197. Mappa Demonstrativo dos objectos recebidos pelo Almoxarifado da Instrucção Publica e distribuidos ás escolas publicas (1898-1903). Arquivo Histórico do Rio Grande do Sul, Porto Alegre. SOUZA, Rosa Fátima. Templos de civilização: a implantação da escola primária graduada no Estado de São Paulo (1890-1910). São Paulo: UNESP, 1998.

SOUZA, Rosa Fátima de. História da Cultura Material Escolar: Um balanço inicial. In: BENCOSTTA, Marcus Levy (Org.). Culturas Escolares, Saberes e Práticas Educativas: itinerários históricos. São Paulo: Cortez, 2007. p. 163-189.

TAMBARA, Elomar. Positivismo e Educação: a educação no Rio Grande do Sul sob o castilhismo. Pelotas: Universitária/UFPel, 1995.

VALDEMARIN, Vera Teresa. Estudando as Lições de Coisas: análise dos fundamentos filosóficos do Método de Ensino Intuitivo. (Coleção Educação Contemporânea). Campinas: São Paulo Autores Associados, 2004. 
28. VEIGA, Cynthia Greive (2000). Cultura material escolar no século XIX, Minas Gerais. In: I Congresso Brasileiro de História da Educação, 2000, Rio de Janeiro. Anais do I Congresso Brasileiro de História da Educação. Rio de Janeiro: UFRJ. Disponível em http://www.sbhe.org.br/novo/congressos/cbhe1/anais/040_cynthia.pdf

VIDAL. Diana Gonçalves \& SILVA, Vera Lucia Gaspar da. Por uma história sensorial da escola e da escolarização. Revista Linhas. Florianópolis, v. 11, n. 02, p. 29 - 45, jul. / dez. 2010.

VIDAL, Diana Gonçalves. No interior da sala de aula: ensaio sobre cultura e prática escolares. Currículo Sem Fronteiras, v. 9, n. 1, p. 25-41, jan/jun 2009. Semestral. Disponível em: <http://www.curriculosemfronteiras.org/vol9iss1articles/2-vidal.pdf>. Acesso em: 20 mar. 2016.

\section{Caroline Braga Michel}

Professora do Instituto Federal Farroupilha (IFFar), Frederico Westphalen, Rio Grande do Sul, Brasil.

\section{Eliane Peres}

Professora Titular da Faculdade de Educação, da Universidade Federal de Pelotas.

\section{Com citar este documento:}

PERES, Eliane; MICHEL, Caroline Braga. Fornecimento de materiais escolares às escolas públicas do Rio Grande do SuL (1882-1913). Reflexão e Ação, Santa Cruz do Sul, v. 27, n. 3, p. 7-23, out. 2019. ISSN 1982-9949. Disponível em: <https://online.unisc.br/seer/index.php/reflex/article/view/13643>. Acesso em doi:https://doi.org/10.17058/rea.v27i3.13643. 